\title{
Professionals' perception on the management of patients with dual disorders
}

This article was published in the following Dove Press journal:

Patient Preference and Adherence

19 September 2016

Number of times this article has been viewed

\author{
Carlos Roncero' ${ }^{1,2}$ \\ Néstor Szerman ${ }^{3}$ \\ Antonio Terán ${ }^{4}$ \\ Carlos Pino 5 \\ José María Vázquez ${ }^{6}$ \\ Elena Velasco ${ }^{7}$ \\ Marta García-Dorado ${ }^{7}$ \\ Miguel Casas ${ }^{1,2}$ \\ 'Addiction and Dual Diagnosis Unit, \\ CIBERSAM, Hospital Vall Hebron, \\ Barcelona Public Health Agency \\ (ASPB), Barcelona, Spain; ${ }^{2}$ Department \\ of Psychiatry, Autonomous University \\ of Barcelona, Barcelona, Spain; \\ ${ }^{3}$ Outpatient Mental Health Clinic El \\ Retiro, Gregorio Marañón University \\ Hospital, Madrid, Spain; ${ }^{4}$ Outpatient \\ Drug Clinic, Hospital San Juan de \\ Dios, Palencia, Spain; ${ }^{5}$ Pontevedra \\ City Council Drug Dependence \\ Service, Galician Health Service \\ (Xunta de Galicia), Pontevedra, \\ Spain; ${ }^{6}$ Outpatient Drug Clinic Sants, \\ Barcelona Public Health Agency \\ (ASPB), Barcelona, Spain; ${ }^{7}$ Medical \\ Affairs Department, Janssen-Cilag \\ S.A., Madrid, Spain
}

Correspondence: Carlos Roncero Addiction and Dual Diagnosis Unit, CIBERSAM, Hospital Vall Hebron, Barcelona Public Health Agency (ASPB), Paseo Vall d'Hebron II9-129, 08035 Barcelona, Spain

Tel +34934894294

Fax +34934894587

Email croncero@vhebron.net
Background: There is a need to evaluate the professionals' perception about the consequences of the lack of therapeutic adherence in the evolution of patients with co-occurring disorders.

Methods: An online survey, released on the Socidrogalcohol [Spanish Scientific Society for Research on Alcohol, Alcoholism and other Drug Addictions] and Sociedad Española de Patología Dual [the Spanish Society of Dual Pathology] web pages, was answered by 250 professionals who work in different types of Spanish health centers where dual diagnosis patients are assisted.

Results: Most professionals perceived the existence of noncompliance among dual diagnosis patients. Almost all of these professionals (99\%) perceived that noncompliance leads to a worsening of the progression of the patient's disorder, in both the exacerbation of mental disorders and the consumption of addictive substances. Most of the professionals $(69.2 \%)$ considered therapeutic alliance as the main aspect to take into account to improve the prognosis in this population. The primary purpose of treatment must be the improvement of psychotic-phase positive symptoms, followed by the control of behavior disorders, reduction of craving, improvement of social and personal performances, and reduction of psychotic-phase negative symptoms.

Conclusion: Most professionals perceived low adherence among dual diagnosis patients. This lack of adherence is associated with a worsening of their disease evolution, which is reflected in exacerbations of the psychopathology and relapse in substance use. Therefore, we propose to identify strategies to improve adherence.

Keywords: dual diagnosis, professionals' perception, noncompliance, decompensation, relapse

\section{Introduction}

Dual disorders (DDs)/dual pathology/co-occurring disorders are the terms commonly accepted within the mental health field to refer to patients suffering from an addictive disorder and other mental disorders. DDs can occur simultaneously or, even more importantly, sequentially throughout their life $\operatorname{span}^{1-4}$ and constitute a serious problem for the public health. ${ }^{5,6}$

Up to $70 \%$ of individuals who have been diagnosed with a substance use disorder (SUD) show a lifetime disorder, that is, a second psychiatric diagnosis throughout their life, ${ }^{7}$ and $50 \%$ of the patients diagnosed with a mental disorder have a history of substance use. ${ }^{8-11}$ In Spain, the prevalence rate of population with a mental disorder associated with SUD ranges between 25\% and 70\%. ${ }^{12-14}$ This percentage varies depending on the research methodology and, especially, the health care center where the study was conducted. ${ }^{15,16}$

Lifetime diagnoses of any mental disorder, and particularly personality disorders and psychotic disorders, were found to be associated with higher prevalence of transition from substance use to SUDs across most categories of substances. ${ }^{17}$ 
This prevalence is higher when tobacco is included and is considered a potentially addictive substance. ${ }^{9}$ Moreover, even though it is widely accepted that the prevalence of DDs is significantly higher in men, ${ }^{18}$ the increasingly high number of diagnosed females in SUD treatment units ${ }^{19}$ has raised controversy. ${ }^{20}$

Underreporting of substance use is common in individuals with severe psychiatric disorders, ${ }^{19}$ and the majority of the studies that have investigated this did not include tobacco.

The dual diagnosis patients' level of insight (patient's awareness) of their psychotic disorder, as occurs with SUD, is low. ${ }^{21}$ Furthermore, the lack of insight is independent of the used substance, whether it is alcohol, which is used very frequently, ${ }^{11,22}$ cocaine, ${ }^{23}$ or cannabis. ${ }^{24}$ Low insight and high polymedication ${ }^{25}$ are the main causes of low therapeutic adherence, particularly in patients with psychosis, ${ }^{26-28}$ increasing the suicide risk. ${ }^{29}$ There is evidence of the relationship between a patient's level of insight of his/her disorder and treatment compliance. ${ }^{30,31}$

A study conducted by Roncero et $\mathrm{al}^{27}$ about health care professionals' perception suggests that $\sim 70 \%$ of dual diagnosis patients do not properly comply with their treatment. This percentage is significantly higher than that observed in patients diagnosed with only one mental disorder, ${ }^{32,33}$ whereas treatment adherence must be improved. ${ }^{34}$ Furthermore, the lack of adherence results in negative prognostic implications, ${ }^{35,36}$ which are even more significant in the dual diagnosis population than in other populations with other mental disorders. ${ }^{37}$

There are limited health resources for the approach to DDs in Spain, which confirms the need for additional efforts and strategies for the treatment of individuals suffering from comorbid disorders. ${ }^{38,39}$ Among other aspects, there is a need for the creation of a register with clear information on the resources available for this group of patients in Spain, ${ }^{40}$ as well as the enhancement of nonpharmacologic therapies. ${ }^{41,42}$

Few studies exist on the perception of the management of pharmacological treatment, where different health professionals ${ }^{27}$ or specific groups of professionals who assist patients suffering from mental disorders ${ }^{43,44}$ or DD patients ${ }^{45}$ are included. Nevertheless, information on professionals' attitude and perception is an important factor to improve the management of schizophrenic or dual diagnosis patients ${ }^{43,46}$ and may also help to improve the negative prognostic implications that are a consequence of noncompliance, optimize the implementation of health and social resources, and produce consensus and protocols to manage this population..$^{12,35}$
The aims of the present study are the evaluation of Spanish professionals' perception about the level of compliance, the factors affecting prognosis and therapeutic adherence, the rate of use of different pharmacologic strategies, and the training of our professionals in this field. Thus, we can expect a perception of low adherence among the participants and also low awareness of the negative consequences associated with noncompliance among the affected patients. On this basis, the recommendation of specific strategies to improve this situation can be developed.

\section{Methodology Study design}

After a thorough review of the literature, a group of clinical and academic experts on DDs (Table 1) designed a survey on adherence and the consequences of therapeutic noncompliance in dual diagnosis (annexed survey).

This online survey, which was open to any professional involved in dual diagnosis assistance who wanted to participate, was made available through the institutional websites of two scientific societies (the Spanish Society of Dual Pathology [SEPD]; www.patologiadual.es and the Spanish Scientific Society for Research on Alcohol, Alcoholism and other Drug Addictions [Sociodrogalcohol]; http://www.socidrogalcohol.org) and was answered between October 1, 2013 and December 31, 2013.

\section{Sample}

The survey was answered by 250 professionals from the following care centers: outpatient drug clinics (47.2\%), mental health centers $(25.2 \%)$, psychiatric hospitalization

Table I List of clinical and academic experts on DDs

\begin{tabular}{ll}
\hline Carlos & Addiction and Dual Diagnosis Unit, Vall d'Hebron \\
Roncero MD & University Hospital - Public Health Agency, \\
& Barcelona (ASPB), CIBERSAM, Autonomous \\
& University of Barcelona, Barcelona, Spain \\
Néstor & Gregorio Marañón University General Hospital, \\
Szerman MD & Madrid, Spain \\
Antonio & San Juan de Dios Health Care Center, \\
Terán MD & Palencia, Spain \\
Carlos & Pontevedra City Council Drug Dependence Service, \\
Pino MD & Galician Health Service (Xunta de Galicia), Spain \\
José María & Outpatient Drug Clinic Sants, ASPB, Spain \\
Vázquez MD & \\
Miguel & Addiction and Dual Diagnosis Unit, Vall d'Hebron \\
Casas MD & University Hospital - ASPB, CIBERSAM, \\
& Autonomous University of Barcelona, \\
& Barcelona, Spain \\
\hline
\end{tabular}

Abbreviation: $\mathrm{DD}$, dual disorder. 
units $(11.2 \%)$, inpatient drug addiction units $(7.2 \%)$, private centers $(6.8 \%)$, and primary care centers $(2.4 \%)$.

Most of the professionals (68.3\%) who participated in the survey were members of scientific societies, mainly the SEPD (56.6\%) and Socidrogalcohol (20.1\%). A total of 54.0\% of the participants were women, and $90.0 \%$ were Spaniards. Most participants $(60.0 \%)$ were older than 45 years.

In all, $57.2 \%$ of the total number of participants had $>15$ years of clinical experience. Most of the professionals $(67.2 \%)$ were working in specialized addiction care units when participating in the survey (Table 2).

This study included professionals from every Spanish regions (autonomous communities) except Cantabria and the autonomous cities of Ceuta and Melilla. The communities with a higher number of participants were Andalucía, Madrid, and Catalonia (Table 3).

The 250 participants included in the survey did not receive any economic compensation for completing the questionnaire.

The questionnaire consisted of 41 questions distributed in eight sections: participant sociodemographic profile (nine questions), prevalence (one question), prognosis improvement and therapeutic goals (two questions), use of substances (one question), disease acknowledgment (three questions), therapeutic adherence (six questions), professional continuing education (two questions), and pharmacological strategies (16 questions). The section on pharmacological strategies included seven subsections: psychopharmacologic groups and multiple therapies (three questions), use of antipsychotics (six questions), use of anticonvulsive euthymic drugs (one question), use of antidepressant drugs (one question), use of modulators of the endogenous opioid system (one question), use of benzodiazepines (three questions), and polymedication (one question).

In 15 questions - excluding the eleven questions aimed to define the sociodemographic profiles - the professionals were asked to sort the answers proposed by the researchers on the basis of their importance or frequency of use. A total

Table 2 Professionals who participated in the survey

\begin{tabular}{ll}
\hline Professionals & Percentage \\
\hline Psychiatrist in addiction units & 18.8 \\
Psychiatrist in mental health & 27.6 \\
General practitioner & 23.2 \\
Resident doctor & 4.0 \\
Clinical psychologist & 15.2 \\
Resident psychologist & 0.4 \\
Qualified nurses & 2.8 \\
Others & 8.0 \\
\hline
\end{tabular}

Table 3 Percentage of participants in different communities

\begin{tabular}{ll}
\hline Communities & Percentage \\
\hline Andalusia & 19.2 \\
Aragon & 1.6 \\
Balearic Islands & 2.0 \\
Canary Islands & 6.0 \\
Cantabria & 0 \\
Castile-Leon & 4.4 \\
Castile-La Mancha & 3.6 \\
Catalonia & 11.6 \\
Ceuta and Melilla & 0 \\
Community of Madrid & 18 \\
Community of Navarre & 2.8 \\
Valencian Community & 8.8 \\
Extremadura & 6.0 \\
Galicia & 4.8 \\
La Rioja & 0.4 \\
Basque Country & 5.2 \\
Principality of Asturias & 1.2 \\
Region of Murcia & 4.4 \\
\hline
\end{tabular}

of 19 questions were responded employing different intervals using Likert scales.

\section{Data analysis}

With the requested information, a descriptive statistical analysis was performed using the SPSS Version 18 statistical software (SPSS Inc., Chicago, IL, USA).

\section{Results}

The 250 survey participants perceived that $40.2 \%$ of the patients in their practice are affected with DDs (Table 4).

\section{Prognosis improvement}

The participants considered that therapeutic alliance is the main aspect to take into account to improve this population's prognosis $(69.2 \%)$, followed by proper and maintained compliance $(66.0 \%)$, patient's disease awareness $(59.2 \%)$, and family support (52.4\%; Table 5).

Table 4 Patients with dual pathology

\begin{tabular}{ll}
\hline Patients \% & Percentage $^{\mathbf{a}}$ \\
\hline $0-10$ & 3.6 \\
$10-20$ & 10.4 \\
$20-30$ & 17.6 \\
$30-40$ & 16.8 \\
$40-50$ & 13.6 \\
$50-60$ & 12.4 \\
$60-70$ & 11.6 \\
$70-80$ & 8.4 \\
$80-90$ & 4.0 \\
$90-100$ & 1.6 \\
\hline
\end{tabular}

Note: apercentage of professionals who had the corresponding percentage range of patients with dual pathology. 
Table 5 Important variables in the prognosis of a dual pathology patient (according to the perceptions of the professionals surveyed)

\begin{tabular}{ll}
\hline Variables & Percentage \\
\hline Therapeutic alliance & 69.2 \\
Continued and adequate compliance of medication & 66.0 \\
Psychoeducational therapy & 25.2 \\
Early drug treatment of the disease & 15.2 \\
Good tolerability of medication & 12.8 \\
Disease awareness & 59.2 \\
Family support & 52.4 \\
\hline
\end{tabular}

\section{Therapeutic goals}

The results of the questionnaire showed that, in the participants' opinion, the primary treatment goal must be the improvement of the psychotic-phase positive symptoms, followed by the control of behavior disorders, reduction of craving, improvement of social and personal performances, and reduction of psychotic-phase negative symptoms (Table 6).

\section{Abuse/addiction substances for which treatment is demanded}

In the participants' opinion, alcohol is the substance mostly used by dual diagnosis patients, followed by cocaine, cannabis, benzodiazepines, heroine, and different psychostimulants, such as 3,4-methylenedioxymethamphetamine and methamphetamines, among others (Table 7).

\section{Level of disease awareness}

In all, $96.0 \%$ of the participants in the survey considered that patients have a deficient level of awareness (insight) of their psychotic disease. Moreover, $87.2 \%$ of the experts also considered that patients have a deficient level of awareness of addictive diseases and only $10.8 \%$ believed that patients are aware of the negative effect of the use of substances on their dual diagnosis (Table 8).

Table 6 Importance of therapeutic targets

\begin{tabular}{ll}
\hline & $\begin{array}{l}\text { Overall } \\
\text { rank }\end{array}$ \\
\hline Improvement of the positive psychotic symptoms & I \\
Control of behavioral disorders & 2 \\
Decreased craving & 3 \\
Improved social and personal functioning & 4 \\
Improvement of the negative psychotic symptoms & 5 \\
Improvement of concomitant affective symptoms & 6 \\
Improvement of anxiety disorders & 7 \\
Relapse prevention & 8 \\
\hline
\end{tabular}

Note: I, the most important and 8 , the least important, according to the perceptions of the professionals surveyed.
Table 7 Substances of abuse/dependence that demand treatment

\begin{tabular}{ll}
\hline Substances abused & $\begin{array}{l}\text { Overall } \\
\text { rank }\end{array}$ \\
\hline Alcohol & 1 \\
Cocaine & 2 \\
Cannabis & 3 \\
Benzodiazepines & 4 \\
Heroin & 5 \\
Other psychostimulants (speed, ecstasy, etc) & 6 \\
Tobacco & 7 \\
Opioid drugs (not heroin) & 8 \\
Pathological gambling & 9 \\
\hline
\end{tabular}

Note: I, the most frequent and 9 , the least frequent, according to the perceptions of the professionals surveyed.

\section{Treatment compliance}

Based on international recommendations, ${ }^{36}$ a patient is defined as "compliant" when taking $\geq 80 \%$ of their medication, "partially compliant" when the intake of medication is between $40 \%$ and $80 \%$, and "noncompliant" when they take $<40 \%$ of the prescribed treatment. In this respect, $10.8 \%$ of the participants stated that their patients are compliant, $63.3 \%$ that their patients are partially compliant, and $25.6 \%$ that their patients are noncompliant (Figure 1).

\section{Hindering pharmacological factors for therapeutic adherence}

Regarding the professionals' clinical experience, the outcomes showed that the association of side effects to the intake of psychiatric drugs is the main explanation for the lack of adherence in this group of patients (Table 9 and Figure 2).

\section{Nonpharmacological strategies for adherence improvement}

Most professionals (73.5\%) affirmed that they are certainly satisfied with the outcomes of the nonpharmacological

Table 8 Degree of awareness (according to the perceptions of the professionals surveyed)

\begin{tabular}{|c|c|c|c|}
\hline & \multicolumn{3}{|l|}{ Value } \\
\hline & $\begin{array}{l}\text { Good } \\
\text { awareness }\end{array}$ & $\begin{array}{l}\text { Intermediate } \\
\text { awareness }\end{array}$ & $\begin{array}{l}\text { No } \\
\text { awareness }\end{array}$ \\
\hline $\begin{array}{l}\text { Degree of awareness of } \\
\text { patients with DD (\%) }\end{array}$ & 4.0 & 67.2 & 28.8 \\
\hline $\begin{array}{l}\text { Degree of knowledge of } \\
\text { patients on the worsening } \\
\text { of their disease due to } \\
\text { substance (\%) }\end{array}$ & 10.8 & 68.4 & 20.8 \\
\hline $\begin{array}{l}\text { Degree of awareness } \\
\text { of patients with active } \\
\text { disease (\%) }\end{array}$ & 12.8 & 64.0 & 23.2 \\
\hline
\end{tabular}

Abbreviation: $\mathrm{DD}$, dual disorder. 


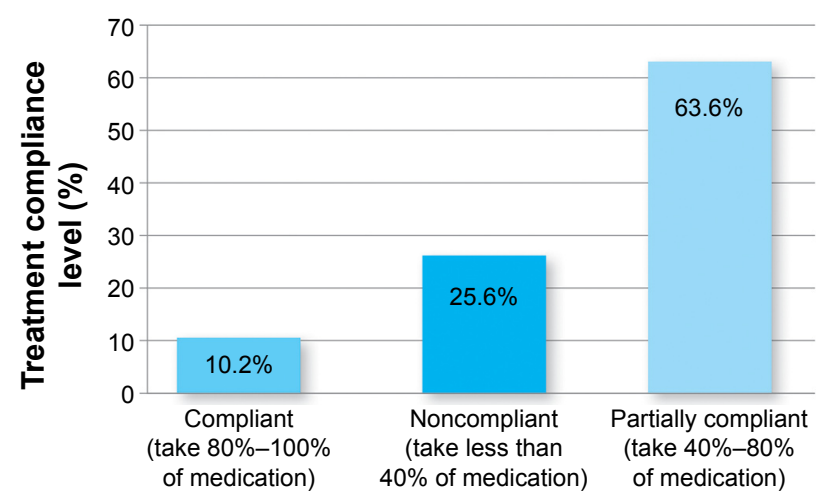

Figure I Level of treatment compliance.

strategies implemented in their dual diagnosis patients. Moreover, the implementation of motivational strategies and psychoeducation for the patient and family are considered the most important nonpharmacological strategies (Table 10).

\section{Use of pharmacological treatments}

The most frequently used drugs for the treatment of dual diagnosis patients are antipsychotics, "commonly used" or "widely used" in $93.2 \%$ of the patients; antidepressants (92.0\%); and anticraving drugs (73.9\%).

In this context, in the participants' opinion, $2.0 \%$ of the patients receive just one drug, as the more common treatment is polymedication. Most of these patients receive a total of three drugs, although almost $25 \%$ of the professionals confirmed that they receive four or more different drugs. This is worth highlighting, since polytherapy significantly affects -"very much" according to $73.6 \%$ of the surveyed participants and "completely" according to $9.6 \%$ of the surveyed participants the patients' quality of life (Figure 3).

\section{Consequences of therapeutic noncompliance}

The vast majority of the participants in the survey (98.8\%) perceived that therapeutic noncompliance worsened the overall course of dual diagnosis patients (Table 11).

Table 9 Pharmacological factors that hinder treatment adherence

\begin{tabular}{ll}
\hline Pharmacological factors & $\begin{array}{l}\text { Overall } \\
\text { rank }\end{array}$ \\
\hline The presence of side effects & $\mathrm{I}$ \\
Inefficiency in controlling symptoms & 2 \\
Complicated therapeutic regimens & 3 \\
Drug interactions & 4 \\
Routes of administration & 5 \\
\hline
\end{tabular}

Note: I, the most important and 5 , the least important, according to the perceptions of the professionals surveyed.

\section{Professionals' educational background}

The most valued training resources were the courses (60.0\%), workshops (54.8\%), and guidelines (47.2\%; Table 12).

\section{Discussion}

Knowing the perception of professionals is very important since, as they are responsible for prescribing and administering the treatment, as well as for the drug efficiency, ${ }^{43,47}$ they are able to detect noncompliant patients and the consequences resulting from their lack of adherence. Thus, they can also identify the necessary interventions to improve this situation.

Professionals perceived that $40.2 \%$ of the patients cared for in different health care settings are affected with DDs. This prevalence is lower than that detected by epidemiologic studies, extending the debate on the underdiagnosis of this disease. In this evaluation, professionals did not usually take into account tobacco, which is also a controversial matter in this field. Nevertheless, the prevalence of DDs may possibly depend on the health care setting where the study is carried out, varying from $24.9 \%$ in psychiatric hospitalization units ${ }^{13}$ and $40 \%$ in emergency units ${ }^{34}$ to $56 \%-67 \%$ in addiction treatment units. ${ }^{14,15}$ Moreover, the survey results also showed alcohol and cocaine, to a lesser degree, as the most used drugs by the DD patients. These data coincide with the studies conducted without including the evaluation of tobacco. ${ }^{7,16,18}$

Professionals' perception on the main therapeutic goals to be achieved to manage dual diagnosis patients should be the improvement of the psychotic-phase positive symptoms, control of behavior disorders, and reduction of craving. These are very important aims, as established by a large number of articles published in the literature. ${ }^{48-50}$

In the CATIE study, ${ }^{51} 60 \%$ of the psychotic patients suffered from SUD sometime in their life, without mention of tobacco. Regardless of the accessibility to health care resources, DD patients present a lower degree of therapeutic adherence than those who have been diagnosed with just one mental disorder..$^{35}$ This coincides with the participants' perception, which shows that $89.2 \%$ of these patients are totally or partially noncompliant. This rate is superior to that observed (68.3\%) in previous similar studies carried out in Spain $^{27}$ with different professionals and in international studies developed exclusively with psychiatrists, varying between $53 \%{ }^{43}$ and $57 \%{ }^{44}$

Participants adduce the occurrence of adverse effects as the main pharmacologic factor to explain for the low rate of 


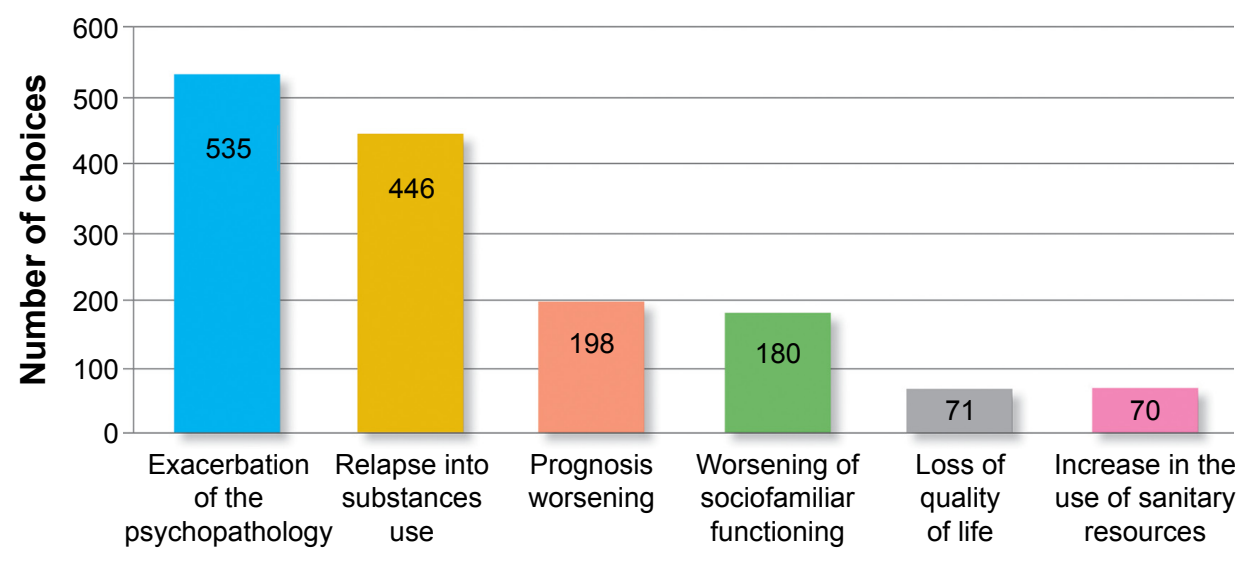

Figure 2 Common consequences of therapeutic noncompliance.

compliance. Likewise, a similar perception is observed when analyzing the patients' ${ }^{52}$ and professionals ${ }^{{ }^{43}}$ opinions. Based on this perception, as concluded in the study performed by Ziedonis et al, ${ }^{42}$ those drugs that may contribute to poor adherence due to their adverse effects should be avoided. Moreover, regarding the rest of the pharmacologic factors that affect compliance, professionals pointed out the inefficacy in controlling the symptoms and the complexity of some treatment regimens. It should be taken into account that DD patients are often a polymedicated population, ${ }^{25}$ and in most cases, they receive two or more antipsychotic drugs. ${ }^{53}$ Therefore, in the professionals' opinion, the prescription of single-dose regimens should be recommended. ${ }^{27}$ However, in this study, $98 \%$ of the professionals treat their patients with more than one drug and $83.2 \%$ with three or more drugs, whereas three is the average number of drugs received by each patient. This is a very important finding, since the majority of the survey respondents perceived that polymedication influences - in varying degrees, "much"

Table 10 Nonpharmacological strategies that favor treatment adherence (according to the perceptions of the professionals surveyed)

\begin{tabular}{ll}
\hline $\begin{array}{l}\text { Nonpharmacological } \\
\text { strategies }\end{array}$ & $\begin{array}{l}\text { Overall } \\
\text { rank }\end{array}$ \\
\hline Motivational strategies & $\mathrm{I}$ \\
Patient and family psychoeducation & 2 \\
Monitoring adherence & 3 \\
Individualized psychological treatment & 4 \\
Simplification of bureaucratic barriers & 5 \\
Rehabilitation services & 6 \\
Group psychotherapy & 7 \\
\hline Level of satisfaction with the & $\%$ \\
nonpharmacological strategies & \\
\hline Very satisfied & 8.8 \\
Quite satisfied & 64.7 \\
Rather dissatisfied & 25.7 \\
Not at all satisfied & 0.8 \\
\hline
\end{tabular}

Note: I, the most important and 7, the least important. or "completely" for $83.2 \%$ of the sample - the patients' quality of life, which is in line with evidence found in the literature. ${ }^{54}$

Likewise, all participants perceived, as evidenced in numerous studies, ${ }^{55-57}$ that nonadherence to treatment determines worse evolution in the prognosis of dual diagnosis patients, very significant in up to $98.8 \%$ of the cases. This is a similar finding to that observed in the study performed by Roncero et al, ${ }^{27}$ in which $96.2 \%$ of the participants considered that noncompliance is severely or very severely related to poor patient evolution. ${ }^{27}$ There is a large number of studies that verify that the lack of adherence is directly associated with a worsening of the disorder's evolution..$^{37,58}$ It should be taken into account that the population affected with severe mental disorders and SUD presents more severe symptoms of the psychopathology and a higher rate of hospitalization, relapse, violence, and suicide ${ }^{29}$ (in short, a worse evolution of the disease) than patients with only one diagnosis. ${ }^{58,59}$ In this context, the participants in this study considered that the worsening of the prognosis is the third most important consequence of noncompliance, only surpassed by an exacerbation of the psychopathology and relapse to substance use.

The difficulties involved in guaranteeing treatment continuity entail a nonnegligible risk of psychopathologic decompensations as well as behavioral ones in DD patients. ${ }^{60}$ This risk together with the relapse in substance consumption is relevant, as shown by several researchers. ${ }^{61-63}$ Nonetheless, in the literature, few objective studies have been conducted on the lack of adherence, whereas we cannot know which one of these is the most frequent. This finding was already detected in a previous study performed by Roncero et al, ${ }^{27}$ in which it was not possible to elucidate whether psychopathologic decompensation is more frequent than relapse in SUD or vice versa. 


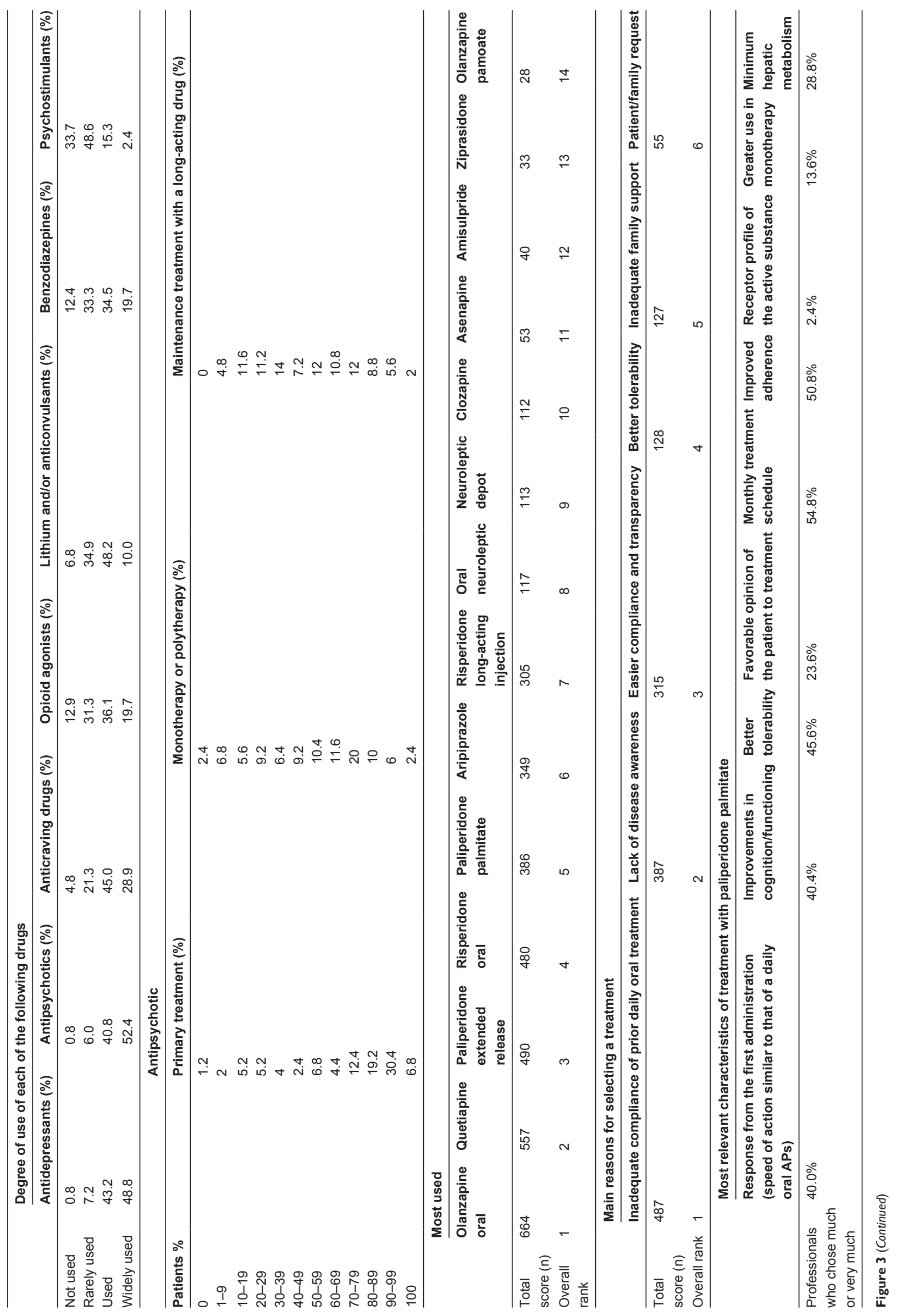




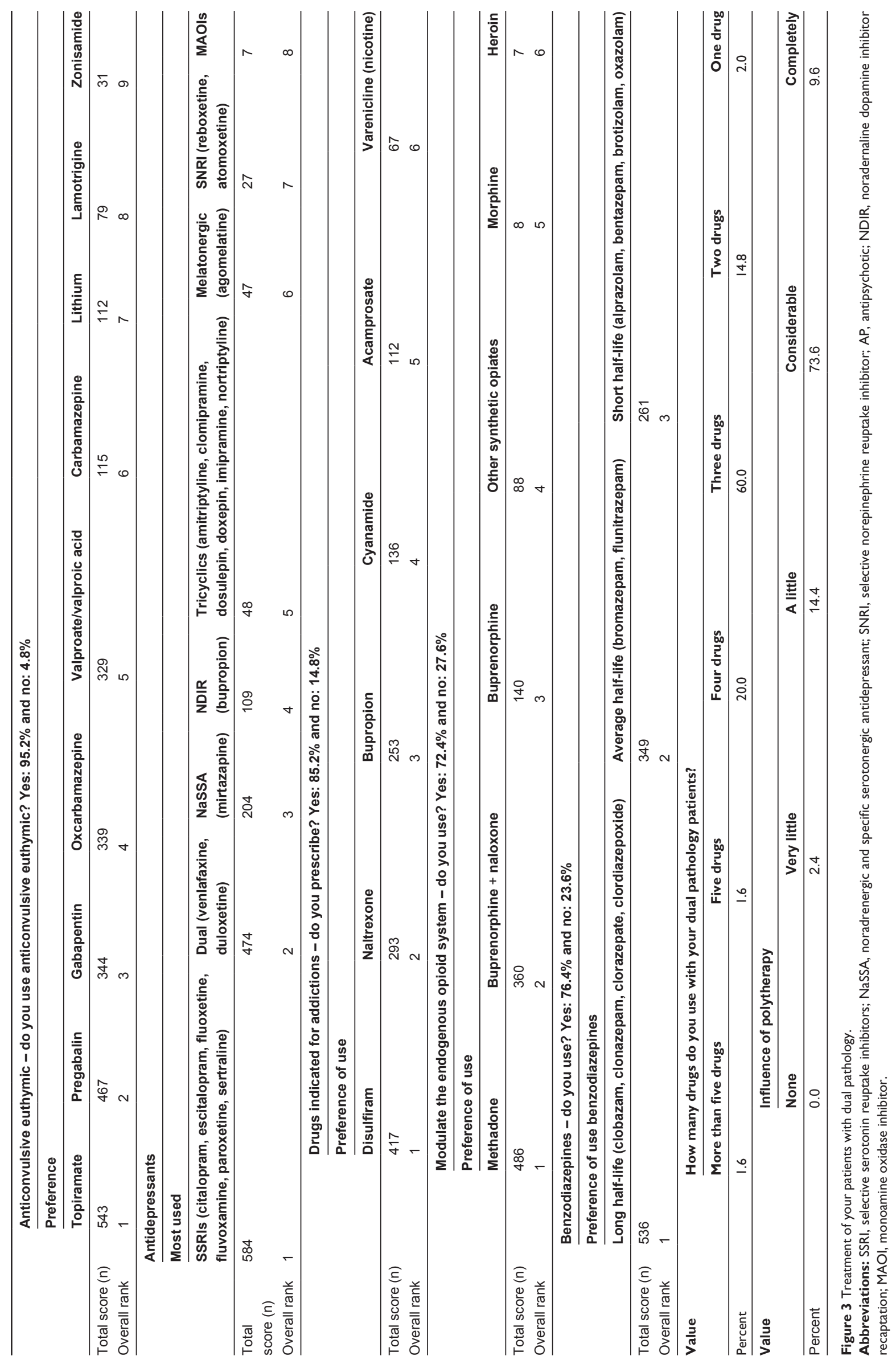


Table I I Degree of deterioration due to therapeutic noncompliance (according to the perceptions of the professionals surveyed)

\begin{tabular}{ll}
\hline Degree of deterioration & Percentage \\
\hline None & 0.0 \\
Slightly & 1.2 \\
Considerably & 40.0 \\
A great deal & 58.8 \\
\hline
\end{tabular}

Noncompliance also involves a worsening of social and family functioning ${ }^{64}$ loss in quality of life, ${ }^{65}$ and an increase in the use of public and private health resources, especially hospitalizations. ${ }^{66}$ These three situations are considered the fourth, fifth, and sixth most important consequences related to the lack of adherence found in our survey.

To improve patients' prognosis, the participants mainly assessed the need for therapeutic alliance $-69.2 \%$ of the participants. This percentage coincides with the research that concluded that establishing a relationship of cooperation between the patient and professional facilitates the achievement of the therapeutic goals. ${ }^{67,68}$ They also assessed the need for treatment adherence $(66.0 \%)$ and patient awareness (insight) of the disease (59.2\%). The latter is correlated with the evolution of the disease and also with the level of compliance. ${ }^{69,70}$ However, only $4 \%$ of the professionals perceived that they are well aware of their patients' psychotic disease, a consideration that in the case of SUD is shared by $12.8 \%$ of the professionals. In addition, according to their clinicians' perception, only $10.8 \%$ of the patients are aware of the damage that the use of substances can produce on their psychotic illness. In European studies, ${ }^{43,44}$ this percentage is $25 \%$.

The survey results also showed the high degree of satisfaction of the professionals with nonpharmacological strategies, emphasizing interventions aimed to optimizing the patient's level of adherence, motivational strategies, as well as patient and family psychoeducation; interventions with a clearly established efficacy as evidenced by several investigations. ${ }^{71,72}$ In this context, however, it should be taken into account that between $20 \%$ and $70 \%$ of the patients who

Table 12 Tools to improve professional development

\begin{tabular}{ll}
\hline Professional development tools & Percentage $^{\mathbf{a}}$ \\
\hline Monographs & 22.8 \\
Manuals & 26.8 \\
Guides & 47.2 \\
Workshops & 54.8 \\
Courses & 60.0
\end{tabular}

Note: apercentage of the professionals who rated the tool as important or very important. start psychosocial therapies in mental health services do not properly comply with them. ${ }^{73}$

In relation to different pharmacologic therapies, antipsychotics, antidepressants, and the so-called anticraving drugs are the mostly used. This finding is similar to the results observed in a study conducted in Spain. ${ }^{20}$ It should be remembered that, in the participants' opinion, the therapeutic goals in this population should include the management of psychotic symptoms as well as decrease of craving. This also coincides with several studies that concluded that the approach to dual diagnosis patients requires combination therapy for addictive behavior and other mental disorders. 35,74 It is not in vain that, among other aspects, the remission of substance dependence or abuse is a critical factor for the proper management of mental disease symptoms. ${ }^{75}$

The findings of this survey also showed that professionals prefer using atypical antipsychotics to the detriment of conventional neuroleptics, a tendency supported by the efficacy of atypical antipsychotics in the approach to dual diagnosis, ${ }^{76-78}$ which is significantly higher than the efficacy observed with classical neuroleptics. ${ }^{75,79}$ Moreover, whereas most patients receive antipsychotic polytherapy, in practically half of the cases, professionals prefer the administration of a maintenance therapy with a long-acting antipsychotic drug. In this context, among other reasons adduced by the participants to explain the need for a treatment with a long-acting antipsychotic, the lack of adherence to daily oral therapies and the lack of awareness of the disease were highlighted. In this respect, it could suggest that this strategy meets the need to improve the current rates of compliance. Moreover, as asserted in the study by van Zaane et al,${ }^{80}$ when treating comorbidities, maintaining the treatment as long as possible should always be considered.

The most frequently used antipsychotics by up to $93.2 \%$ of the professionals are daily oral olanzapine, quetiapine, extended-release paliperidone, daily oral risperidone, and paliperidone palmitate, all of which have been proved to be effective in the management of dual diagnosed patients. ${ }^{76,77,81,82}$ In line with this, whenever there is an antipsychotic drug with oral and long-acting administration available, it is important to consider long-acting treatments versus daily intake options, as the first provides a better response in dual diagnosis patients. ${ }^{83}$ In the professionals' perception and taking into account the improvement of psychotic-phase positive symptoms, the control of behavior disorders and the decrease of craving are the main therapeutic goals in dual diagnosis patients. Paliperidone palmitate has proven to be the most used long-acting antipsychotic and is perceived as a drug that offers better tolerability than all the other antipsychotics. 
Its advantages include improving cognition/functioning and a simple route of administration; ${ }^{77}$ both characteristics are considered to be the main pharmacologic factors required to facilitate therapeutic compliance.

Antidepressants were used by $92 \%$ of the participants. The study results showed that professionals preferred using selective serotonin reuptake inhibitors and, to a lesser degree, dual-action drugs such as noradrenergic and specific serotonergic antidepressants. Moreover, 85.2\% of the participants affirmed that they prescribe drugs indicated for addiction treatments, especially disulfiram and, less frequently, naltrexone and bupropion, very effective drugs for addiction treatments; $;{ }^{84} 95.2 \%$ prescribe anticonvulsive euthymic drugs, mostly topiramate, to manage their patients, although there is limited evidence about its appropriateness for the treatment of addictions; ${ }^{85}$ and $72.5 \%$ prescribe modulators of the endogenous opioid system for opioid-dependent patients, mainly methadone, the combination of buprenorphine and naloxone, which have been shown useful for dual diagnosis patients. ${ }^{86}$ In this context, it is important to point out the high prescription rates of benzodiazepines for the population affected with dual diagnosis: $76.4 \%$ of the professionals prescribe long half-life benzodiazepines to their patients, a much higher rate than that observed in a previous international study. ${ }^{87}$ This occurs in spite of the fact that the use of benzodiazepines can increase the risk of abuse potential and therefore generate a new problem with abuse/dependence, as stated in the research performed by Brunette et al. ${ }^{88}$ This is why careful assessment and close monitoring are recommended in the use of benzodiazepines, if not totally avoided, in dual diagnosis patients. ${ }^{12}$ Furthermore, professionals also found that $59 \%$ of their patients use benzodiazepines for self-medication. This result is consistent with studies in which the use of benzodiazepines without prescription has been evaluated. ${ }^{89,90}$

Finally, the professional's education is relevant. ${ }^{46,91}$ The present study shows that $60 \%$ of the participants considered that courses are the main educational tool, followed by workshops and access to clinical practice guidelines. In fact, this appreciation is similar to that observed in previous works focusing on professionals' perception..$^{27,44}$

\section{Strengths and limitations}

As for the limitations of this study, it should be noted that the participants in this open online survey are highly motivated professionals very interested in participating in a study on DDs. Therefore and since results may not represent the opinion of all of the professionals who care for DD patients, it is necessary to compare the outcomes with the perception of other groups of professionals with a different profile. Also, it has been considered that generally the strength of studies based on open conducting online surveys is not too significant, although the choice of this methodology is supported by numerous previous studies published in the literature. ${ }^{27,43,44}$

Nevertheless, due to the importance of the professionals' opinion on health care planning, the relevance of the topic, the number of participants, and the fact that they work in a variety of dual diagnosis patient health care units, these results should be highly valued. Furthermore, due to the few works previously published in the literature on this topic, they should be especially valued. ${ }^{27,43,44}$

\section{Conclusion}

Professionals perceived that most dual diagnosis patients do not comply with the prescribed treatment. This lack of adherence is associated with a worsening of their disease evolution, which is reflected in exacerbations of the psychopathology and relapse in substance consumption. Undoubtedly, these circumstances lead to a worse prognosis; therefore, it is very necessary to implement pharmacologic and nonpharmacologic strategies in order to improve the rate of compliance. Taking into account the main objectives of the surveyed professionals, when treating their patients, one should include not only effective pharmacological therapies for symptom control, with a moderate side effect profile, which have proven to reduce the employment of health care resources and improve the patient's functioning, but also nonpharmacological therapies, which also improve therapeutic compliance, as these are influential factors for a better prognosis.

\section{Acknowledgments}

We would like to thank Entheos Editorial Group members for their assistance in writing this article. We would also like to thank all the authors who responded to the survey and agreed to being named: José Antonio Acal Gutiérrez, José Ángel Alcalá Partera, Francisco Carlos Alcántara López, Juan Manuel Alonso Ramis, Benjamín Altozano Aguila, Isabel Álvarez, Adolfo Álvarez Villarino, Raquel Álvarez García, Joan Alvarós, Ana Aparicio, Rosario Azcorbebeitia Lamiquiz, Gerardo Aznar Rivera, Diana Bachiller, Abel Baquero, Carmen Barral, Diego Barral Tafalla, Ma Ángeles Barreda, Ana M ${ }^{\mathrm{a}}$ Bastida de Miguel, Cipriano Beccar Varela, Patricia Bernal, $\mathrm{M}^{\mathrm{a}}$ Asunción Berrueco Quintero, Luisa $\mathrm{M}^{\mathrm{a}}$ Blanco Caramés, Octavio Blanes Pla, $\mathrm{M}^{\mathrm{a}}$ Dolors Bosch Balcells, Victoria Boticario, Ma Amparo Buján López, David Cáceres Anillo, Pilar Calvo Estopiñán, Teresa Carot Subirats, 
Federico Guillermo Castellanos Gutiérrez, Ricardo Castillo Falla, María de Guía Castro Granados, Olga Chapinal, Antonio Evaristo Clavero Machado, Luciano Cobos Luna, María Conde, Gloria Cordeiro Crespo, Isabel María de Haro García, Antonio de María García, Francisco de Orta Sequera, $\mathrm{M}^{\mathrm{a}}$ Belén del Amo, Celia del Pino Lidón, Juan Carlos Díaz del Valle, Enrique Aníbal Díaz Ramos, Helen Dolengevich, Álvaro José Doña Díaz, Marisa Dorado, Caridad Espinosa Delgado, , Esther Estaún, Jaime A. Fernández, José Manuel Fernández Fernández, Nieves Fernández Rodríguez, José Luis Frías Pulido, Paula María Fuertes, Óscar David Galera, Gladys Gamboa, Angustias García, José María García Basterrechea, Maruja García Gómez, Dionisio García Osuna, María Llanyra García Ullán, Pilar Gardeta Sabater, Vicente Garijo García, Alfonso Gil Martínez, José Manuel Giménez García, José Luis Gómez Juárez, Esperanza González Marín, Juan Bautista González Palomino, Begoña Gonzalvo Cirac, Alfredo Gurrea Escajedo, Inmaculada Gutiérrez Porcel, Ana María Hernández Cordero, Miguel Ángel Hernández Las Heras, Isabel Hernández Otero, Agustín Ma Herrero Matías, Ana Jiménez Bidón, Juan Manuel Jiménez-Lerma, Yacksary Juárez Ortega, Miguel Landabaso, Rodrigo Leal, Isabel López Escamilla, David López Gómez, Alex Raúl Lorie Vega, Eloina Mallada, Letizia Irene Manchado López, Julia Elena Márquez-Arrico, Esther Marticorena, Lucía Martín Calvo, Manuel José Martín Esquinas, José Manuel Martínez Delgado, Francisco Ignacio Mata Cala, Piedad Medina Álvarez, Desiderio Mejías, Irene Milla, Argiñe Mingo Idoyaga, Diana Miranda Abal, Fabiola Modrego, Antonio Jesús Molina, Hugo Mongay Sánchez-Gijón, Esther Montero Manzano, Cristina Montilla Bueno, Josué MonzónDíaz, María Antonia Mora, Juan Andrés Moreno Nieto, Jordi Morillo Vera, Fernando Morrás, Raimundo Juan Muscellini, Adrián Neyra del Rosario, $\mathrm{M}^{\mathrm{a}}$ de la Concepción Nogales Romero, Beatriz Nogueras Ormanzábal, Ma Pilar Notario Poves, Daniel Núñez Arias, Jesús Núñez García, Enriqueta Ochoa Mangado, M ${ }^{a}$ Soledad Olmeda, Carlos Ordóñez, Teresa Orengo Caus, María Bettina Ortiz-Medina, Ana $\mathrm{M}^{\mathrm{a}}$ Palé Esteve, Gemma Parramón, Juan Manuel Pascual Paño, Susana Pelegrina Gómez, Salvador Peralta, Ma Pilar Pérez, Joseba Pérez Acha, Blanca Pérez Molina, Jesús Pérez-Pazos, Alicia Picazo Menéndez, Carlos José Pino Serrano, Silvia Piñeiro Carrió, Gabriela Pizzi Guevara, Sofía Prieto Sebastiá, Carmen Quesada Romero, Emilio Rato, Analeda Regalado, Manuel Reus Martínez, Joseba Rey, Laura Reyes, Manuela Reyes Requena, Antonia Rico Soliveres, León Riera Fueyo, María Ríos, María Peñitas Ríos Muñoz, Carmen Ripoll, Ma Ángeles Rodríguez, Carles Rodríguez, María José Rodríguez Melgar, María Soledad Rodríguez Verdugo, Alfonso
Rodríguez-Palancas Palacios, Emma Román Fernández, José Paulo Romero Flores, Samuel Leopoldo Romero Guillena, Néstor Romo, J. Javier Rosa, Alfonso Rosa Ruiz, Carmen Rubio Otero, Estela Sáez, José María Salgado, Pilar San Juan, Amparo Sánchez, Ma del Mar Sánchez, Pablo Sánchez Arrobas, Paloma Sánchez de la Nieta Aragonés, Sabrina Sánchez Quintero, Ana María Sánchez Viñas, Mario SánchezMorate Tristante, Armando Santiago, Ma Luisa Sanz, Juan Sanz Arroyo, Catherine Séiquer de la Peña, Daniel Serrani, Ma Carmen Serván, Antonio Silvestre Segovia, Fco. Javier Suárez Guzmán, Marta Elsa Suárez Merialdo, José Torroba Molina, Carmen Tosio, Javier Gerardo Trejo Canseco, Marta Vallcanera Cabrera, Luis Vasallo, Urbano Vázquez Fernández, José María Vázquez Vázquez, Dolores Velo, Albert Vicente València, Carlos Villegas, María de Gracia Viseu Pinheiro Lopes do Rego, and Augusto Zafra.

\section{Disclosure}

The editorial support of this article, as well as the survey on which it was based, were financed by Janssen. Carlos Roncero has received fees to give talks for Janssen-Cilag S.A., Bristol-Myers Squibb, Ferrer-Brainpharma, Pfizer, Reckitt Benckiser/Indivior, Lundbeck, Otsuka, Servier, Lilly, Shire, GlaxoSmithKline, and AstraZeneca. He has received financial compensation for his participation as a member of the Janssen-Cilag S.A., Lilly, and Shire boards. He has carried out the PROTEUS project, which was funded by a grant from Reckitt Benckiser. Néstor Szerman has received speaker fees from Janssen-Cilag S.A., Lundbeck, Servier, and Lilly. He has received financial compensation for his participation as a member of the Janssen-Cilag S.A. and Lundbeck boards. Antonio Terán has received fees to give talks for Lilly, Janssen, Pfizer, Shire, Lundbeck, GlaxoSmithKline, and Servier. He has received financial compensation for his participation as a member of the Janssen-Cilag S.A., Lilly, Reckitt Benckiser, and Lundbeck boards. Carlos Pino has received financial compensation from the following laboratories: Janssen-Cilag S.A., Lilly, Servier, Ferrer, Lundbeck, Almirall, Reckitt Benckiser, Wyeth, and Esteve. He has received financial compensation for his participation as a member of the Janssen-Cilag board. José María Vázquez has received financial compensation from the following laboratories: Janssen-Cilag S.A., Lilly, Lundbeck, Bristol Myers Squibb, Reckitt Benckiser, and Juste. He has received financial compensation for his participation as a member of the Janssen board. Elena Velasco and Marta García-Dorado work in the Medical Affairs Department of Janssen-Cilag S.A. Miguel Casas has received fees to give talks for JanssenCilag S.A., Bristol-Myers Squibb, Ferrer-Brainpharma, 
Pfizer, Reckitt-Benckiser, Lundbeck, Otsuka, Servier, Lilly, Shire, GlaxoSmithKline, Rovi, and Adamed. He has received financial compensation for his participation as a member of the Janssen-Cilag S.A., Lilly, and Shire boards. The authors have no other relevant affiliations or financial involvement with any organization or entity with a financial interest in or financial conflict with the subject matter or materials discussed in the manuscript apart from those disclosed, and report no other conflicts of interest in this work.

\section{References}

1. Szerman N, Martinez-Raga J, Peris L, et al. Rethinking dual disorders/ pathology. Addict Disord Their Treat. 2013;12:1-10.

2. Szerman N, Martinez-Raga J. Two different mental disorders? Advancing in dual diagnosis. Dual Disord. 2015;8:2.

3. Volkow ND. Addiction and co-occurring mental disorders. Director's perspective. Natl Inst Drug Abuse NIDA Notes. 2007;21:2.

4. World Health Organization [webpage on the Internet]. Lexicon of Alcohol and Drug Terms. Geneva: 1994. Available from: http://whqlibdoc.who.int/publications/9241544686.pdf?ua=1. Accessed February 22, 2015.

5. McGovern MP, Lambert-Harris C, Gotham HJ, Claus RE, Xie H. Dual diagnosis capability in mental health and addiction treatment services: an assessment of programs across multiple state systems. Adm Policy Ment Health. 2014;41(2):205-214.

6. McHugo GJ, Drake RE, Brunette MF, Xie H, Essock SM, Green AI. Enhancing validity in co-occurring disorders treatment research. Schizophr Bull. 2006;32(4):655-665.

7. Arias F, Szerman N, Vega P, et al. Cocaine abuse or dependency and other psychiatric disorders. Madrid study on dual pathology. Revista de Psiquiatría y Salud Mental (Barc.). 2013;6(3):121-128.

8. Compton WM, Conway KP, Stinson FS, Colliver JD, Grant BF. Prevalence, correlates, and comorbidity of DSM-IV antisocial personality syndromes and alcohol and specific drug use disorders in the United States: results from the national epidemiologic survey on alcohol and related conditions. J Clin Psychiatry. 2005;66(6):677-685.

9. Lev-Ran S, Le Foll B, McKenzie K, George TP, Rehm J. Cannabis use and cannabis use disorders among individuals with mental illness. Compr Psychiatry. 2013;54(6):589-598.

10. Saha TD, Chou SP, Grant BF. Toward an alcohol use disorder continuum using item response theory: results from the national epidemiologic survey on alcohol and related conditions. Psychol Med. 2006; 36(7):931-941.

11. Santamarina S, Iglesias C. Schizophrenia and frequent psychotropic substance use in our environment. Adicciones. 2001;13(4):385-391.

12. Casas M, Franco MD, Goikolea JM, et al. Spanish working group on bipolar disorders in dual diagnosis. Bipolar disorder associated to substance use disorders (dual diagnosis). Systematic review of the scientific evidence and expert consensus. Actas Españolas de Psiquiatría. 2008;36(6):350-361.

13. Rodríguez-Jiménez R, Aragüés M, Jiménez-Arriero MA, et al. Dual diagnosis in psychiatric inpatients: prevalence and general characteristics. Investigación Clínica. 2008;49(2):195-205.

14. Roncero C, Fuste G, Barral C, et al; PROTEUS Study Investigators. Therapeutic management and comorbidities in opiate-dependent patients undergoing a replacement therapy programme in Spain: the PROTEUS study. Heroin Addict Relat Clin Probl. 2011;13(3):5-16.

15. Pereiro C, Pino C, Flórez G, Arrojo M, Becoña E; COPSIAD Group. Psychiatric comorbidity in patients from the addictive disorders assistance units of Galicia: the COPSIAD study. PLoS One. 2013;8(6):e66451.

16. Szerman Bolotner N, Arias Horcajadas F, Vega Astudillo P, et al. Pilot study on the prevalence of dual pathology in community mental health and substance misuse services in Madrid. Adicciones. 2011;23(3):249-255.
17. Lev-Ran S, Imtiaz S, Rehm J, Le Foll B. Exploring the association between lifetime prevalence of mental illness and transition from substance use to substance use disorders: results from the national epidemiologic survey of alcohol and related conditions (NESARC). Am J Addict. 2013;22(2):93-98.

18. Delegación del Gobierno para el Plan Nacional sobre Drogas [Government Delegation for the National Drugs Plan]. PNSD. Madrid: Ministerio de Sanidad y Consumo, Informe; 2009. Available from: http://www.pnsd.msssi.gob.es/. Accessed August 16, 2016.

19. Miquel L, Roncero C, López-Ortiz C, Casas M. Epidemiological and diagnostic axis I gender differences in dual diagnosis patients. Adicciones. 2011;23(2):165-172.

20. Gual A. Dual diagnosis in Spain. Drug Alcohol Rev. 2007;26(1): 65-71.

21. Bahorik AL, Newhill CE, Queen CC, Eack SM. Under-reporting of drug use among individuals with schizophrenia: prevalence and predictors. Psychol Med. 2014;44(1):61-69.

22. Yen CF, Hsiao RC, Chen CC, et al. The role of insight to alcohol use disorders in insight to schizophrenia. Compr Psychiatry. 2009;50(1): $58-62$.

23. Moeller SJ, Maloney T, Parvaz MA, et al. Impaired insight in cocaine addiction: laboratory evidence and effects on cocaine-seeking behaviour. Brain. 2010;133(pt 5):1484-1493.

24. Miller R, Caponi JM, Sevy S, Robinson D. The Insight-adherenceabstinence triad: an integrated treatment focus for cannabis-using first-episode schizophrenia patients. Bull Menninger Clin. 2005;69(3): 220-236.

25. Grau-López L, Roncero C, Daigre C, et al. Observational study on medications prescribed to dual-diagnosis outpatients. $J$ Addict Med. 2014;8(2):84-89.

26. McEvoy JP, Lieberman JA, Stroup TS, et al; CATIE Investigators. Effectiveness of clozapine versus olanzapine, quetiapine, and risperidone in patients with chronic schizophrenia who did not respond to prior atypical antipsychotic treatment. Am J Psychiatry. 2006;163(4): 600-610.

27. Roncero C, Gómez-Baeza S, Vázquez JM, et al. Perception of Spanish professionals on therapeutic adherence of dual diagnosis patients. Actas Españolas de Psiquiatría. 2013;41(6):319-329.

28. Stroup TS, Lieberman JA, McEvoy JP, et al; CATIE Investigators. Effectiveness of olanzapine, quetiapine, risperidone and ziprasidone in patients with chronic schizophrenia following discontinuation of a previous atypical antipsychotic. Am J Psychiatry. 2006;163(4):611-622.

29. Szerman N, Lopez-Castroman J, Arias F, et al. Dual diagnosis and suicide risk in a Spanish outpatient simple. Subst Use Misuse. 2012;47(4):383-389.

30. Francis JL, Penn DL. The relationship between insight and social skill in persons with severe mental illness. J Nerv Ment Dis. 2001; 189(12):822-829.

31. Vender S, Poloni N. Is the insight a favourable prognostic factor in the treatment of mental disorders? Recenti Prog Med. 2006;97(10): $565-570$.

32. Farren CK, Hill KP, Weiss RD. Bipolar disorder and alcohol use disorder: a review. Curr Psychiatry Rep. 2012;14(6):659-666.

33. Torrens M, Rossi PC, Martinez-Riera R, Martinez-Sanvisens D, Bulbena A. Psychiatric co-morbidity and substance use disorders: treatment in parallel systems or in one integrated system? Subst Use Misuse. 2012;47(8-9):1005-1014.

34. Roncero C, Rodríguez-Cintas L, Barral C, et al. Treatment adherence to treatment in substance users referred from psychiatric emergency service to outpatient treatment. Actas Españolas de Psiquiatría. 2012;40(2):63-69.

35. Roncero C, Barral C, Grau-Lopez L, et al. Protocols of dual diagnosis intervention in schizophrenia. Addict Disord Their Treat. 2011;10(3): 131-154.

36. Velligan DI, Weiden PJ, Sajatovic M, et al. Assessment of adherence problems in patients with serious and persistent mental illness: recommendations from the expert consensus guidelines. $J$ Psychiatr Pract. 2010;16(1):34-45. 
37. Sánchez-Peña JF, Alvarez-Cotoli P, Rodríguez-Solano JJ. Psychiatric disorders associated with alcoholism: 2 year follow-up of treatment. Actas Españolas de Psiquiatría. 2012;40(3):129-135.

38. Spanish Society of Dual Disorders [webpage on the Internet]. Proposal to the Strategy on Mental Health NHS. 2014. Available from: http:// www.patologiadual.es/docs/propuesta_AEPD_estrategia_salud $\% 20$ mental_sns.pdf. Accessed November 10, 2014.

39. Szerman N, Vega P, Grau-López L, et al. Dual diagnosis resource needs in Spain: a national survey of professionals. J Dual Diagn. 2014; 10(2):84-90.

40. Roncero C, Vega P, Martínez-Raga J, et al. Professionals' perceptions about healthcare resources for co-occuring disorders in Spain. Int J Ment Health Syst. 2014;8(1):35.

41. Warren JI, Stein JA, Grella CE. Role of social support and self-efficacy in treatment outcomes among clients with co-occurring disorders. Drug Alcohol Depend. 2007;89(2-3):267-274.

42. Ziedonis DM, Smelson D, Rosenthal RN, et al. Improving the care of individuals with schizophrenia and substance use disorders: consensus recommendations. J Psychiatr Pract. 2005;11(5):315-339.

43. Olivares JM, Alptekin K, Azorin JM, Cañas F, Dubois V, Emsley R Psychiatrists' awareness of adherence to antipsychotic medication in patients with schizophrenia: results from a survey conducted across Europe, the Middle East, and Africa. Patient Prefer Adherence. 2013;7: 121-132.

44. Vieta E, Azorin JM, Bauer M, et al. Psychiatrists' perceptions of potential reasons for non- and partial adherence to medication: results of a survey in bipolar disorder from eight European countries. J Affect Disord. 2012;143(1-3):125-130.

45. Chan KK, Chin QP, Tang JY, et al. Perceptions of relapse risks following first-episode psychosis and attitudes towards maintenance medication: a comparison between nursing and social work professionals. Early Interv Psychiatry. 2011;5(4):324-334.

46. Adams MW. Comorbidity of mental health and substance misuse problems: a review of workers' reported attitudes and perceptions J Psychiatr Ment Health Nurs. 2008;15(2):101-108.

47. Oller-Canet S, Fernández-San Martín MI, García-Lecina R, et al. Do depressed patients comply with treatments prescribed? A cross sectional study of adherence to the antidepressant treatment. Actas Españolas de Psiquiatría. 2011;39(5):288-293.

48. Lehman AF, Steinwachs DM. Translating research into practice: the Schizophrenia Patient Outcomes Research Team (PORT) treatment recommendations. Schizophr Bull. 1998;24(1):1-10.

49. Martinotti G, Andreoli S, Di Nicola M, Di Giannantonio M, Sarchiapone M, Janiri L. Quetiapine decreases alcohol consumption, craving, and psychiatric symptoms in dually diagnosed alcoholics. Hum Psychopharmacol. 2008;23(5):417-424

50. Tiet QQ, Mausbach B. Treatments for patients with dual diagnosis: a review. Alcohol Clin Exp Res. 2007;31(4):513-536.

51. Swartz MS, Wagner HR, Swanson JW, et al. Substance use in persons with schizophrenia: baseline prevalence and correlates from the NIMH CATIE study. J Nerv Ment Dis. 2006;194(3):164-172.

52. Wong MM, Chen EY, Lui SS, Tso S. Medication adherence and subjective weight perception in patients with first-episode psychotic disorder. Clin Schizophr Relat Psychoses. 2011;5(3):135-141.

53. Baldessarini RJ, Perry R, Pike J. Factors associated with treatment nonadherence among US bipolar disorder patients. Hum Psychopharmacol Clin Exp. 2008;23(2):95-105.

54. Hajjar ER, Cafiero AC, Hanlon JT. Polypharmacy in elderly patients. Am J Geriatr Pharmacother. 2007;5(4):345-351.

55. Salloum IM, Moss HB, Daley DC. Substance abuse and schizophrenia: impediments to optimal care. Am J Drug Alcohol Abuse. 1991;17(3): 321-336.

56. Dixon L. Dual diagnosis of substance abuse in schizophrenia: prevalence and impact on outcomes. Schizophr Res. 1999;35(suppl):S93-S100

57. Nieuwlaat R, Wilczynski N, Navarro T, et al. Interventions for enhancing medication adherence. Cochrane Database Syst Rev. 2014; 11:CD000011.
58. Usieto EG, Perniab MC, Pascual C. Comprehensive intervention in psychotic disorders with substance use disorder comorbid pathology from a dual unit. Rehabil Psicosoc. 2006;3(1):26-32.

59. Błachut M, Badura-Brzoza K, Jarzab M, Gorczyca P, Hese RT. Dual diagnosis in psychoactive substance abusing or dependent persons. Psychiatr Pol. 2013;47(2):335-352.

60. Szerman N, Álvarez-Vara C, Casas M. In: Glosa, editor. Patología dual en esquizofrenia. Opciones terapéuticas. Barcelona: Editorial Glosa; 2007.

61. Benjamin AB, Mossman D, Graves NS, Sanders RD. Tests of asymptom checklist to screen for comorbid psychiatric disorders in alcoholism. Compr Psychiatry. 2006;47(3):227-233.

62. Driessen M, Veltrup C, Wetterling T, John U, Dilling H. Axis I and axis II comorbidity in alcohol dependence and the two types of alcoholism. Alcohol Clin Exp Res. 1998;22(1):77-86.

63. Pérez-Gálvez B, Vicente-Manzanaro MP, García-Fernández L, RomeroEscobar C, Oliveras-Valenzuela MA. Prevalence of psychopathology in alcohol-dependents outpatients. Trastornos Adictivos. 2008;10: 42-48.

64. Soyka M. Substance misuse, psychiatric disorder and violent and disturbed behavior. Br J Psychiatry. 2000;176:345-350.

65. Bellack AS, Bennett ME, Gearon JS, Brown CH, Yang Y. A randomized clinical trial of a new behavioral treatment for drug abuse in people with severe and persistent mental illness. Arch Gen Psychiatry. 2006; 63(4):426-432.

66. Hunt GE, Bergen J, Bashir M. Medication compliance and comorbid substance abuse in schizophrenia: impact on community survival 4 years after a relapse. Schizophr Res. 2002;54(3):253-264.

67. Redko C, Rapp RC, Elms C, Snyder M, Carlson RG. Understanding the working alliance between persons with substance abuse problems and strengths-based case managers. J Psychoactive Drugs. 2007;39(3):241-250.

68. Tetzlaff BT, Kahn JH, Godley SH, Godley MD, Diamond GS, Funk RR. Working alliance, treatment satisfaction, and patterns of posttreatment use among adolescent substance users. Psychol Addict Behav. 2005; 19(2):199-207.

69. Maremmani AG, Rovai L, Rugani F, et al. Correlations between awareness of illness (insight) and history of addiction in heroin-addicted patients. Front Psychiatry. 2012;3:61.

70. Gajski A, Karlović D. Assessment of nurse attitudes on psychiatric patient compliance with pharmacotherapy. Acta Clin Croat. 2008;47(3): 149-153.

71. Crowley V, Rose J, Smith J, Hobster K, Ansell E. Psycho-educational groups for people with a dual diagnosis of psychosis and mild intellectual disability: a preliminary study. J Intellect Disabil. 2008;12(1):25-39.

72. Martino S, Carroll K, Kostas D, Perkins J, Rounsaville B. Dual diagnosis motivational interviewing: a modification of Motivational Interviewing for substance-abusing patients with psychotic disorders. J Subst Abuse Treat. 2002;23(4):297-308.

73. Gearing RE, Townsend L, Elkins J, El-Bassel N, Osterberg L. Strategies to predict, measure, and improve psychosocial treatment adherence. Harv Rev Psychiatry. 2014;22(1):31-45.

74. Pettinati HM, O'Brien CP, Dundon WD. Current status of cooccurring mood and substance use disorders: a new therapeutic target. Am J Psychiatry. 2013;170(1):23-30.

75. Kelly TM, Daley DC, Douaihy AB. Treatment of substance abusing patients with comorbid psychiatric disorders. Addict Behav. 2012; 37(1):11-24.

76. Benabarre A, Castro P, Sánchez-Moreno J, et al. Efficacy and safety of long-acting injectable risperidone in maintenance phase of bipolar and schizoaffective disorder. Actas Españolas de Psiquiatría. 2009; 37(3):s143-s147.

77. Hough D, Lindenmayer JP, Gopal S, et al. Safety and tolerability of deltoid and gluteal injections of paliperidone palmitate in schizophrenia. Prog Neuro Psychopharmacol Biol Psychiatry. 2009;33(6): 1022-1031.

78. Núñez Domínguez LA. Atypical neuroleptic in cannabis users with schizophrenia. Adicciones. 2001;13(1):67-73. 
79. San L, Arranz B, Martinez-Raga J. Antipsychotic drug treatment of schizophrenic patients with substance abuse disorders. Eur Addict Res. 2007;13(4):230-243.

80. van Zaane J, van den Brink W, Draisma S, Smit JH, Nolen WA. The effect of moderate and excessive alcohol use on the course and outcome of patients with bipolar disorders: a prospective cohort study. J Clin Psychiatry. 2010;71(7):885-893.

81. Murthy P, Chand P. Treatment of dual diagnosis disorders. Curr Opin Psychiatry. 2012;25(3):194-200.

82. Potvin S, Stip E, Lipp O, et al. Quetiapine in patients with comorbid schizophrenia-spectrum and substance use disorders: an open-label trial. Curr Med Res Opin. 2006;22(7):1277-1285.

83. Green AI, Brunette MF, Dawson R, et al. Long-acting injectable vs oral risperidone for schizophrenia and co-occurring alcohol use disorder: a randomized trial. J Clin Psychiatry. 2015;76(10):1359-1365.

84. Green AI, Noordsy DL, Brunette MF, O'Keefe C. Substance abuse and schizophrenia: pharmacotherapeutic intervention. J Subst Abuse Treat. 2008;34(1):61-71.

85. Miller J, Roache J. Benefits of topiramate treatment in a dual-diagnosis patient. Psychosomatics. 2009;50(4):426-427.
86. Maremmani AG, Rovai L, Pani PP, et al. Do methadone and buprenorphine have the same impact on psychopathological symptoms of heroin addicts? Ann Gen Psychiatry. 2011;10:17.

87. Clark RE, Xie H, Brunette MF. Benzodiazepine prescription practices and substance abuse in persons with severe mental illness. J Clin Psychiatry. 2004;65(2):151-155.

88. Brunette MF, Noordsy DL, Xie H, Drake RE. Benzodiazepine use and abuse among patients with severe mental illness and co-occurring substance use disorders. Psychiatr Serv. 2003;54(10):1395-1401.

89. Fernandez Sobrino AM, Fernandez RV, Lopez CJ. Benzodiazepine use in a sample of patients on a treatment program with opiate derivatives (PTDO). Adicciones. 2009;21(2):143-146.

90. Roncero C, Grau-López L, Díaz-Morán S, Miquel L, Martínez-Luna N, Casas M. Evaluation of sleep disorders in drug dependent inpatients. Medicina Clínica. 2012;138(8):332-335.

91. Brems C, Johnson ME, Bowers L, Lauver B, Mongeau VA. Comorbidity training needs at a state psychiatric hospital. Adm Policy Ment Health. 2002;30(2):109-120.
Patient Preference and Adherence

\section{Publish your work in this journal}

Patient Preference and Adherence is an international, peer-reviewed, open access journal that focuses on the growing importance of patient preference and adherence throughout the therapeutic continuum. Patient satisfaction, acceptability, quality of life, compliance, persistence and their role in developing new therapeutic modalities and compounds to optimize

\section{Dovepress}

clinical outcomes for existing disease states are major areas of interest for the journal. This journal has been accepted for indexing on PubMed Central. The manuscript management system is completely online and includes a very quick and fair peer-review system, which is all easy to use. Visit http://www. dovepress.com/testimonials.php to read real quotes from published authors. 